\title{
Body Image Perception: Gender Differences among University Students
}

\author{
Lia Breda-Vicentini \\ Paulista University - UNIP, Sorocaba, Brazil
}

Renan Rossi

Sorocaba Physical Education College - FEFISO, Brazil

Angela Luciana De-Bortoli

Freelance Researcher, Brazil

Robelius De-Bortoli (Corresponding author)

Federal University of Sergipe, Brazil

E-mail: ladec.ufs@gmail.com

Received: 20/06/2020

Accepted: 21/08/2020

Published: 01/09/2020

Volume: 1 Issue: 1

How to cite this paper: Breda-Vicentini, L., Rossi, R., De-Bortoli, A. L., \& R., De-Bortoli, R. (2020). Body Image Perception: Gender Differences among University Students. Journal of Practical Studies in Education 1(1), 15-19

DOI: https://doi.org/10.46809/jpse.v1i1.9

Copyright $\odot 2020$ by author(s) and Global Talent Academy Ltd. This work is licensed under the Creative Commons Attribution International License (CC BY 4.0).

http://creativecommons.org/licenses/by/4.0/

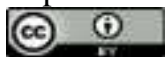

\begin{abstract}
Body image is an important component of the complex mechanism of personal identity. The subjective component of body image refers to a person's satisfaction with their body size or specific parts of your body. The aim of this study was to verify the ability to correlate body image with the actual image of others. This study presents empirical characteristics and crosssectional study. Twenty-nine subject adults, students in Physical Education course and volunteers were selected randomly. The instrument used was based on the Scale of Silhouettes specially constructed for this study. Results showed that women were statistically different from men with average responses always with higher values. While we treat only the individual and their weight, the social standards accepted continue to exert a negative influence on people and their behavior.
\end{abstract}

Keywords: Obesity, Perception, Academic, BMI, Gender, Self-Image

\section{Introduction}

"Body image is an important component of the complex mechanism of personal identity. The subjective component of body image refers to a person's satisfaction with their body size or specific parts of their body" (Kakeshita, \& Almeida, 2006, p. 498). This definition of body image triggers a series of investigations on human behavior in relation to its self-image.

With an interest in quantifying this procedure and offering a reliable instrument for measurement, Cooper, Taylor, Cooper, and Fairburn (1987) developed the Body Shape Questionnaire (BSQ) that seeks to incorporate other aspects of self-image, such as the influence of the social environment.

The BSQ is basically an instrument where the subject projects his body image in comparison with a series of drawings that suggest, among various forms, one that resembles it. Subsequently, a validation process for this type of instrument followed, which came to be called the Scale of Silhouettes Drawings. 
Almeida, Santos, Pasian, and Loureiro (2005) tell us that the Scale of Silhouettes Drawings contributed to the investigation of aspects related to the perceptions of normal, real and ideal body size and shape, allowing the association of such assessment to the weight classes, determined by the BMI, allowing, still, the identification of conflicting choice indicators regarding the assessment of the real and the desirable in a group of overweight and obese women.

A study by Kakeshita and Almeida (2006) tries to validate the scale of silhouettes as an instrument for analyzing the perception of body image in university students and finds a good relationship between tests and retests. It is clear that researchers are concerned with understanding how people see themselves.

Likewise, Bosi, Raggio Luiz, Morgado, Costa, and Carvalho (2006) carried out a study that aimed to identify selfperception of body image among nutrition students. In this study specifically, the authors found an interesting finding: a group of nutrition students with adequate weight showed dissatisfaction with their body image. The fact that people with weight appropriate to their stature and within the standards recommended to describe healthy people brings us to a real problem and possible object of investigation. Would the instrument be limited in its structure and conclusions or would it be more suitable for specific groups, whether age, sex or cultural, for example?

Another question that seems pertinent is whether the self-image and the image that is made of others remain at the same level of correlation. It is important to identify possible patterns of body image perception between genders. It is also important to expand instruments and investigation procedures, especially if they are customized for each group. The results obtained with customized instruments optimize behavioral diagnostics, generating more accurate information for the professionals they use for their work, whether in clinical or social situations.

Based on the possible fragility of the self-image assessment instruments, the objective of this study was to verify how University students correlate the body image of other people with the real image, comparing results between men and women.

\section{Method}

This study was carried out during the offer of a discipline, subject of undergraduate teaching, in a Physical Education course and presents characteristics of an empirical and transversal study, where the responses of the subjects to a group of options are compared and verified how close they are to the right answers.

Twenty-nine subjects, adults, university students and volunteers were randomly selected to participate, of which 10 indicated they were female, 18 male and 1 replied "I don't know / I don't want to answer". The sample had an average age of $22.22 \pm 5.54$ years, an average weight of $71.13 \pm 13.15 \mathrm{~kg}$ and an average height of $1.70 \pm 0.08 \mathrm{~m}$, which resulted in an average Body Mass Index (BMI) $24.56 \pm 3.59 \mathrm{~kg} / \mathrm{m} 2$.

2.1. Instruments

The instrument used was based on the Scale of Silhouettes and specially built for this study. It was constructed as follows: into the sample group of Physical Education students formed over 180 days ago, 10 subjects were randomly chosen. Two photographs were taken for each of these, one in front and the other in profile, using only a shirt and shorts, according to their usual clothing in the classroom.

The photographs were inserted in a sequence of slides using the Microsoft Power Point for Windows program. The original photograph was duplicated and placed side by side. To the left (of the observer) the same photograph was presented, however with distortion of $-10 \%,-20 \%$ and $-30 \%$ in its real width. To the right (of the observer) the same original photograph was presented with distortion of $+10 \%,+20 \%$ and $+30 \%$ of the original width, making a slide with 8 photos, from the smallest to the largest in which the two central photographs corresponded to the original format.

The slides were presented in sequence for each subject, first from the front and later in profile. Each slide was projected for 7 seconds and the volunteer subjects responded to the following statement: "Considering the numbers" 1 "to" 8 ", mark with an" $\mathrm{x}$ "the number corresponding to the Image you believe to be the real Image of the evaluated subject! "

The answer form contained the indication of each individual in the photo separately and the 8 options to mark an "X". At the end, there were demographic data of sex, date of birth, weight and height evaluated.

The results were transferred to a Microsoft Excel spreadsheet and the responses between the male and female groups were compared. Initially, a descriptive statistic and a Student $t$ test were performed between the means of the groups by gender.

\section{Results}

Table 1 shows the means and standard deviations of age, height and BMI of the individuals that make up the study sample. As it is a group of undergraduate university students from a public university in the first year of the course, it is clear that the average age is above what would be the normality desired, since the education of the student predicts that the end of pre-university education will be completed. at 17 years old. A certain heterogeneity of the sample is also perceived because the standard deviation was 5.54 years.

The standard deviation of height $(0.08 \mathrm{~m})$ indicates homogeneity, however the standard deviation of weight $(13.15 \mathrm{~kg})$ seems to indicate an extremely heterogeneous sample in this aspect. As a consequence, the BMI also presents some heterogeneity. 
Table 1: Means and standard deviations of the subjects' age, weight, height and BMI.

\begin{tabular}{lllll} 
& Age & Weight & Stature & BMI \\
\hline Average & 22.22 & 71.13 & 1.70 & 24.56 \\
\hline Standard Deviation & 5.54 & 13.15 & 0.08 & 3.59 \\
\hline
\end{tabular}

Once the subjects' responses were recorded, the means and standard deviations for each slide were determined, dividing into two groups, the female and the male. In figure 1, it is possible to visually verify that the average of the responses of the female subjects has higher values than the male subjects, in all questions.

Performed the Student's t-test for two samples in pairs for means, it is observed that there are statistically significant differences between the sexes with $\mathrm{p}<0.01$. Pearson's correlation was also performed to verify similarity between response patterns and the values indicate a correlation of 0.77 , which indicates a relative parallelism in the interpretations of the photographs between the sexes.

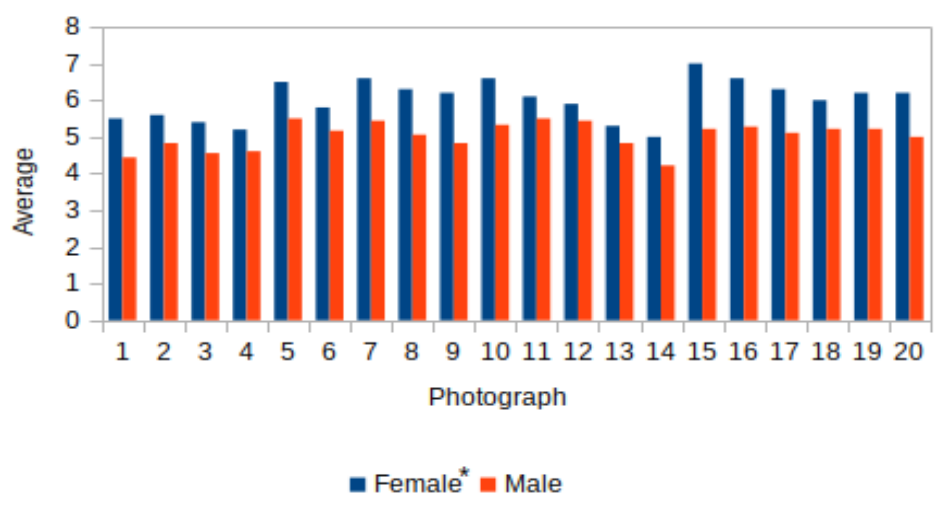

Figure 1: Means and Standard Deviations by gender, where * $p<0.01$

When analyzing the responses according to the increased or decreased perception, we can see in Table 2 how the subjects behaved according to their sex. In general terms, the perception is increased in both sexes, but it is clear that the female subjects have their perception more distorted.

Table 2: Number of responses by sex with decreased, real and increased view of the silhouettes.

\begin{tabular}{cccc} 
& Female & Male & Total \\
\hline Small Image & 12 & 59 & 71 \\
\hline Real Image & 48 & 177 & 225 \\
\hline Enlarged Image & 140 & 144 & 284 \\
\hline
\end{tabular}

If we consider that overweight and obese boys and girls are more likely to be exposed to bullying than their normal weight peers (Brixval, Rayce, Rasmussen, Holstein, \& Due, 2011), it is evident that in this studied group there is a perception that their colleagues are above their own real weight. Figure 2 shows the percentages of responses according to the identification of the actual silhouette, decreased or increased.

Among the responses, $49 \%$ indicated a deformed photograph with increased silhouette, which worries, because without considering possible vision problems, it makes us believe that something is out of normal.

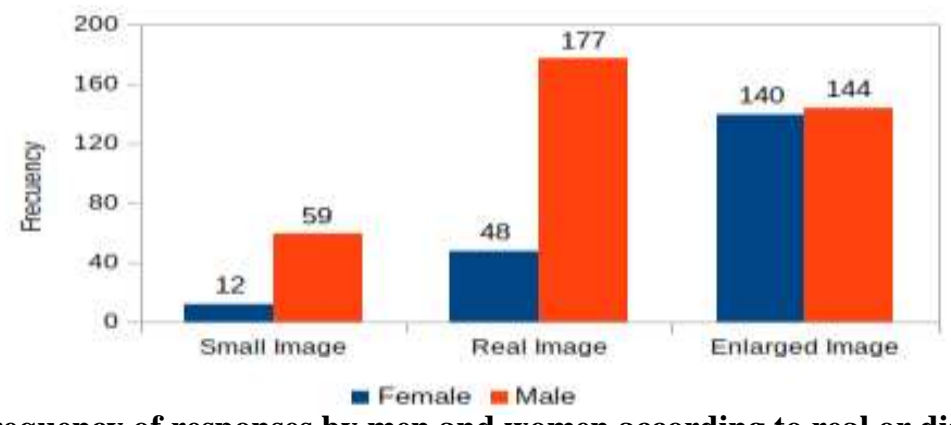

Figure 2: Frequency of responses by men and women according to real or distorted image perception. 
When comparing the results between the sexes, we noticed some interesting differences in the groups. Men differ from women mainly in their perception that others have bigger silhouettes than the real one (Figure 3) with $70 \%$ of the answers. Only $6 \%$ of female responses point to errors in reducing the subjects' silhouette. Among men, the highest percentage of responses came from identifying the real silhouette of the subjects (46.6\%). Both groups coincide with few of their responses, decreasing the subjects' silhouette.

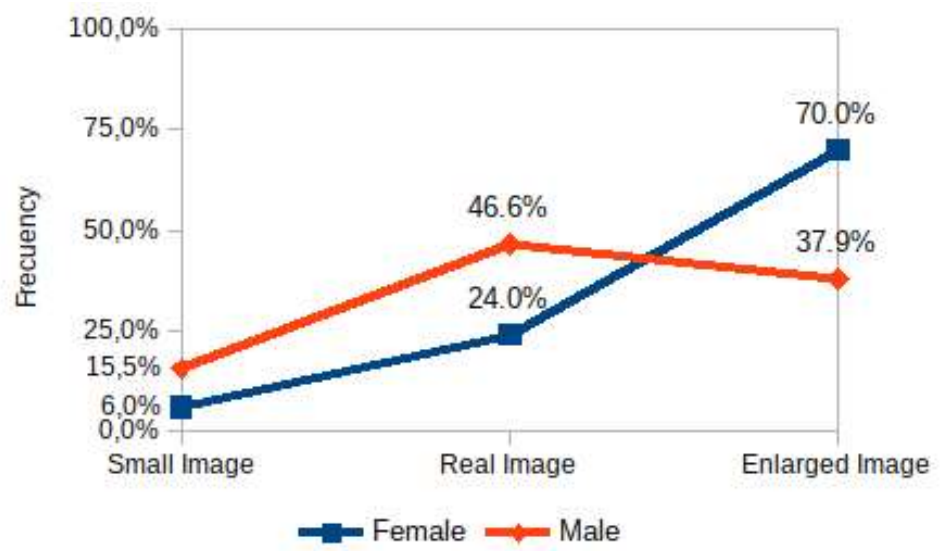

Figure 3: Comparison of the responses of men and women according to real or distorted image perception.

\section{Discussion}

The data confirm the trend found in a study by Bun, et al. (2011) with children aged 14 years. They showed a greater lag in self-image than at 10 years old. $32.55 \%$ of girls have a negative image while boys at this age only $15.8 \%$ have a negative image.

The cultural factor seems to be present in the fact that the perception is increased of the body size of the others, because the contemporary patterns are of thin silhouettes, regardless of age or indirectly to the evolution of the course (Bosi, Luiz, Uchimura, \& Oliveira, 2008)

Almeida et al. (2005) when they say that "the perception of body size has been associated with strong cultural values" (p.28), a position corroborated by Wickrama and Bryant (2012) who, studying American couples of African descent, found relationships between depression and Body Mass Index outside normal standards.

Studies by Gonçalves, Barbosa, Rosa, \& Rodrigues (2008) demonstrate that socio-cultural influences and social pressures that are imposed by the media, affect boys and girls differently in their body image. For girls there is a tendency to demand lean and slender bodies and for boys strong and muscular bodies. Some young people are discriminated against and excluded when they run away from an ideal standard of body presentation required implicitly in social relationships, even if this escape is caused by the perception of others more than by reality.

Due to the fact that the subjects participating in the research are adults, university students, perhaps they fit what Liechty and Yarnal (2010) point out in their studies when they say that with age, women value appearance more than health or internal characteristics.

We are talking about the perception of the image of others, but studies by Rech, Araújo, and Vanat (2010) show dissatisfaction with body image and desire to change it to adapt to current social standards. This body dissatisfaction was more evident among women, and they had a higher level of dissatisfaction than men, which somewhat confirms the comparative results of sex in our study.

This statement corresponds to what Aguilar, Barneveld, Gonzalez-Arratia, and Unikel-Santoncini (2010) state in their studies. The results reveal that body dissatisfaction is a factor present in most women in the sample studied by them, expressing high percentages of body dissatisfaction, but it does not confirm Stockton et al. (2009) when they say that girls with a higher BMI present a greater discrepancy in their body image. In our study, the average BMI of the female subjects who answered the questions was $23.06 \mathrm{~kg} / \mathrm{m}^{2}$ and the male was $25.34 \mathrm{~kg} / \mathrm{m}^{2}$.

After analyzing the responses and comparing the profile between the sexes, it was clearly noticed that there is a discrepancy in the perception of the body image of others. It was also found that women were statistically different from men with average responses always with higher values.

The sample size is small to seek deeper conclusions, but the study creates some scientific gaps that deserve to be considered. So, if people see others as heavier than the real thing; if overweight people are more prone to bullying, then who should be treated: what is overweight or what looks at it?

As long as we deal only with the individual and his weight, accepted social standards will continue to have a negative influence on people and their behavior. To be more objective, perhaps the "disease" of obesity is also in the eye of the beholder, alongside the anthropometric and body composition parameters. 


\section{References}

Aguilar, B. R., Barneveld, H. O., Gonzalez-Arratia, N. I., \& Unikel-Santoncini, C. (2010). Desarrollo y validación de una escala para medir imagen corporal en mujeres jóvenes. Salud Mental, 33(4), 325-332.

Almeida, G. A. N., Santos, J. E., Pasian, S. R., \& Loureiro, S. R. (2005). Percepção de Tamanho e Forma Corporal de Mulheres: Estudo Exploratório. Psicologia em Estudo, Maringá, 10(1), 27-35.

Bosi, M. L. M., Luiz, R. R., Uchimura, Y. K., \& Oliveira, P. F. (2008). Comportamento alimentar e imagem corporal entre estudantes de educação física. Jornal Brasileiro de Psiquiatria, 57(1), 28-33.

Bosi, M. .L. M., Raggio Luiz, R., Morgado, C. M. C., Costa, M. L. S., \& Carvalho, R. J. (2006). Autopercepção da imagem corporal entre estudantes de nutrição: um estudo no município do Rio de Janeiro. Jornal Brasileiro de Psiquiatria, 55(2), 108-113.

Brixval, C. S., Rayce, S. L. B., Rasmussen, M.; Holstein, B. E., \& Due, P. (2011). Overweight, body image and bullying-an epidemiological study of 11- to 15-years olds. European Journal of Public Health, 22(1), 126-130.

Bun, C. J. E., Schwiebbe, L., Schütz, F. N., Bijlsma-Schlösser, J. F. M., \& Hirasing, R. A. (2011). Negative body image and weight loss behaviour in Dutch school children. European Journal of Public Health, 22(1), 130-133.

Cooper, P. J., Taylor, M., Cooper, Z., \& Fairburn, C. G. (1987). The development and validation of the Body Shape Questionnaire. International Journal Eat Disorder, (6), 485-94.

Gonçalves, D. T., Barbosa, P. M.; Rosa L. C. L., \& Rodrigues, M. A. (2008);.Comportamento anoréxico e percepção corporal em universitários. Jornal Brasileiro de Psiquiatria, 57(3), 166-170.

Kakeshita, I. S., \& Almeida, S. S. (2006). Relação entre índice de massa corporal e a percepção da auto-imagem em universitários. Revista de Saúde Pública, 40(3), 497-504.

Liechty, T., \& Yarnal, C. M (2010). Older women's body image: a lifecourse perspective. Ageing \& Society, (30), 11971218.

Rech, R. C., Araújo, S. D. E., \& Vanat, R. J. (2010). Autopercepção da imagem corporal em estudantes do curso de educação física. Revista Brasileira de Educação Física e Esporte, São Paulo, 24(2), 285-92.

Stockton, M. B., Lanctot, J. Q., McClanahan, B. S., Klesges, L. M., Klesges, R. C., Kumanyika, S., \& Sherrill-Mittleman, D. (2009). Self-perception and Body Image Associations with Body Mass Index among 8-10-year-old African American Girls. Journal of Pediatric Psychology, 34(10), 1144-1154.

Wickrama, T., \& Bryant, C. M. (2012). Association Between Body Mass Index and Depressive Symptoms of African American Married Couples: Mediating and Moderating Roles of Couples' Behavioral Closeness. Journal of Family, 33(5), 613-638. 